\title{
Strategies to Express Time in a Tenseless Language: Turkish Sign Language (TID)*
}

\author{
Serpil Karabüklü \\ Purdue University, Lyles-Porter Hall, 3149, West Lafayette, IN, 47906, USA \\ serpilkarabuklu@gmail.com \\ (Received 15 October 2017; accepted 15 May 2018)
}

\begin{abstract}
The studies on how time is expressed in TiD have different results: Gökgöz (2009) proposes that head nod is a tense morpheme while Arı (2012) and Dikyuva et al. (2015) claim that TíD is a morphologically tenseless language. This study shows that TiD is a morphologically tenseless language based on the occurrence of head nod with different verb types. It is also proposed that tense of a sentence is expressed via time adverbials and shown which syntactic positions time adverbials occur in. Lastly, timelines in TID, which are only reported on in a few studies, are described based on the placement of time adverbials in the signing space. It is also shown that different time spans require different timelines to be used.
\end{abstract}

Keywords: time, tense, Turkish Sign Language (TID), timelines, head nod

\section{Zamansız Bir Dilde Zamanı İfade Etmenin Yöntemleri: Türk İşaret Dili} (TID)

ÖZ: TİD'de zamanın nasıl ifade edildiği üzerine olan çalışmalar farklı sonuçlar göstermiştir: Gökgöz (2009) baş sallamanın zaman biçimbirimi olduğunu savunurken Arık (2012) ve Dikyuva ve diğ. (2015) TíD'in biçimbirimsel olarak zamansız bir dil olduğunu iddia etmektedirler. $\mathrm{Bu}$ çalışma, baş sallamanın farklı eylem türleri ile görünüşüne dayanarak TİD'in biçimbirimsel olarak zamansız bir dil olduğunu göstermektedir. Ayrıca, bir tümcenin zamanının zaman belirteçleri ile ifade edildiği önerilmekte ve zaman belirteçlerinin hangi sözdizimsel konumlarda bulundukları gösterilmektedir. Son olarak, birkaç çalışmada bahsedilen TíD’deki zaman çizgileri zaman belirteçlerinin işaret uzamına yerleştirilmesine dayanarak

\footnotetext{
* I am grateful for the support of the signers who participated to this study, reviewers whose comments helped the manuscript fully developed, and Boğaziçi Sign Language Lab and Purdue Sign Language Linguistics Lab members, and my peers Jian Jiao and Taryn McDowell for their valuable comments. All errors are mine. This study was supported by TÜBİTAK research project number 114E263: Avatar Animation and Machine Translation System from Turkish to Turkish Sign Language. The corpus used in the study was created with the fund by TÜBİTAK research Project number 111K314: A Model for Sign Language Reference Grammars: Methods for the Description and Analysis of Sign Systems in the Light of Turkish Sign Language.
} 
tanımlanmakta, farklı zaman aralıklarının farklı zaman çizgilerini gerektirdiği de gösterilmektedir.

Anahtar sözcükler: zaman, Türk İşaret Dili (TID), zaman çizgileri, baş sallama

\section{Introduction}

Sign languages are considered as tenseless languages, which means that tense inflection on the verb has not been observed for most of them (Binnick, 1991; Cogen, 1977; Meir \& Sandler, 2008; Pfau, Steinbach, \& Woll, 2013; Sinte, 2013). For TID, Gökgöz (2009) proposed that head nod accompanying the verb can convey tense; however, other studies reported that TID does not have a verbal inflection for tense (Arik, 2012; Dikyuva et al., 2016). Instead, TID benefits from time adverbials to convey time as generally observed in sign languages (Cabeza Pereiro \& Fernandez Soneira, 2004; Pfau et al., 2013).

The placement of time adverbials in the signing space yields timelines, which is another strategy to convey time (Cabeza Pereiro \& Fernandez Soneira, 2004; Meir \& Sandler, 2008; Le Guen, 2012; Pfau et al., 2013; Sinte, 2013). Sinte (2013) describes how different timelines are realized in various sign languages. She concludes with six different timelines and a plan in spatial mapping observed in sign languages (pp. 206-7, 2013). For TID, Ar1k (2012) is the first study which explores one such timeline in TID. He concludes that the line is not productively used since the signs of days and months are body anchored and cannot appear on the timeline. However, this study will show that another timeline is used when days or months are part of a time span as in 'from now to March'.

Building upon the studies on TID, the current study has three aims: Firstly, it will show that head nod does not systematically appear with each verb type based on its event structure, thus it is not a tense marker. The second aim is to show that time of a clause in TID is conveyed with time adverbials and time frame does not change unless a new time adverbial is introduced in the discourse. Lastly, timelines observed in this study will be described based on Sinte's (2013) study.

The paper will present the literature in the following subsections: Section 1.1 explores how time is encoded in sign languages. Section 1.2 presents studies on time and tense in TİD. After presenting the methodology in Section 2 , Section 3 will present the findings. I conclude with the results and the interpretations of my findings in Section 4. 


\subsection{How Time is Encoded in Sign Languages}

Sign languages are reported to convey time information via time adverbials, timelines and nonmanual markers (Cogen, 1977; Meir \& Sandler, 2008; Pfau, Steinbach, \& Woll, 2013; Sinte, 2013). Even though some studies discuss the possibility that ASL, LIS and BSL may have tense inflection on the verb (Sutton-Spence and Woll, 1999; Jacobowitz and Stokoe, 1988; Zucchi, 2006) sign languages are reported not to have tense inflection on the verb.

A clause can be interpreted within a time-frame which is established by a time adverbial within the same clause, in the previous sentence or somewhere else in the discourse. The default interpretation of a sentence without a time reference is present tense (Cabeza Pereiro \& Fernandez Soneira, 2004; Pfau et al., 2013), which will be discussed with TíD examples in Section 2.

Another commonly observed strategy for encoding time across sign languages is the use of timelines (Cabeza Pereiro \& Fernandez Soneira, 2004; Meir \& Sandler, 2008; Le Guen, 2012; Pfau et al., 2013; Sinte, 2013). Pfau et al. (2013) define 'timeline' as using space metaphorically in time expressions (p. 189). In timelines, time is considered as a line and events are considered to lie on this line. Although Pfau et al. (2013) claim that timelines are culturespecific, the most frequently observed timeline is the one in which the signer's body behaves as a reference point for the simple tenses and forms a distinction between past and future. This timeline extends from the space behind the signer's body over the shoulder to his front on the ipsilateral side (Pfau et al., 2013). When the signer's body is viewed as a reference point and coincides with the present, the space behind his body represents past and the space in the front future.

Sinte (2013) summarizes the different timelines used across sign languages and offers six different types of timelines (Figure 1). While a given language may not use all of these timelines, a sign language uses at least one. The current study will report the timelines which are observed in TID in an existing corpus and in this research study. All timelines observed in this study are provided in Appendix 1.

To briefly summarize Sinte's (2013) proposal, Line 1 is the one lying on the dominant side of the signer parallel to the ground. It is realized via the placement of some time adverbials on the signing space. To illustrate, YESTERDAY or BEFORE is signed via backward movement over the shoulder whereas TOMORROW or LATER is signed via forward movement. Adverbials like NOW or TODAY is signed by downward movement in front of the signer (Pfau et al., 2013). Line 2 is used to sequence the events relative to a reference point. In addition to situating events related to a reference point, Line 3 is used in some sign languages to express calendar units or adpositional signs such as BEFORE and AFTER on the contralateral side. Line 4 is a blending of the first three lines as a mixed line. It is used to talk 
about the events in very near future. Days of the week are located on Line 5 also called the 'top-down-line' which is observed in NGT and LSQ (Sinte, 2013). The last line, Line 6, is oriented from bottom to top in contrast to Line 5. This line is observed in the lexical signs such as GROW or LIVE. The movement path of these signs is from the bottom to top, which iconically represents the growing size of one's body as the body grows from short to tall $^{1}$. Lastly, in addition to six timelines, a "Plan" is used for calendar units as a schedule of a week or a year.

\section{Figure 1. Sinte's (2013) timelines found in different sign languages}

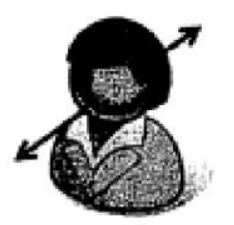

Line 1

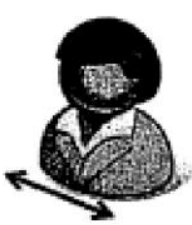

Line 2

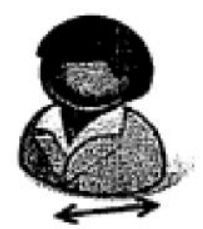

Line 3

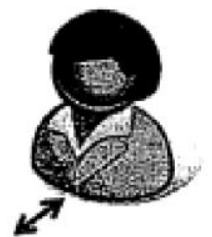

Line 4

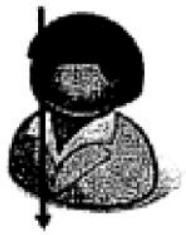

Line 5

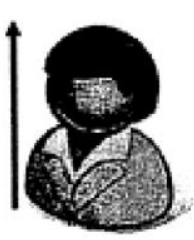

Line 6

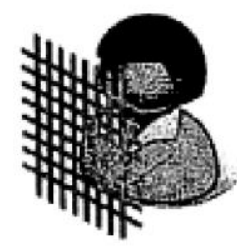

Plan

Timelines presented in Figure 1 can be also considered in terms of how the notion of time is reflected in the language. Clark (1973) presents two metaphors for the representation of time in the language, moving ego and moving time. Line 6 can be an example to moving ego where time is considered as constant but the ego moves through the time. Differently, Line 1 is a representative example for time moving where ego is constant and time is moving. In Line 1, the signer's body refers to the present, the back refers to the past and the front to the future. Clark (1973), furthermore, notes that time is one dimensional and represented as one dimensional in spoken languages. Interestingly, this study will present the lines derived from the combinations of lines like Line 1 and Line 6. This leads to an interesting question as whether the one-dimensional or multidimensional representation is due to the modality difference, which would be the subject of another study.

1 I thank the reviewer who brings this to my attention. 
Another consideration can be how the events are represented in terms of the signer's perspective; character or observer perspective (Özyürek \& Perniss, 2011). In character perspective, the event is represented from the character's point while the event is represented through an outer perspective in observer perspective. Line 1 and Line 6 can be considered as character perspective and other lines are presented from observer perspective. In this respect, Line 6, which is used for lexical signs like GROW or LIVE, can be considered as character perspective since the path of the movement represents the change both in time and the subject's body size. On the other hand, other lines represent the observer perspective since the signer presents the event within a larger perspective by zooming out via locating the reference points onto the signing space like Line 2.

\subsection{Studies on Time and Tense in TID}

Zeshan $(2002,2003)$ is the first to describe how tense and aspect are encoded in TID. She proposes that time information is given via time adverbials. Building upon this knowledge, Gökgöz (2009) argues that tense is also expressed nonmanually. He observes that repetitive head nod expresses future (Figure 2), while single head nod expresses past (Figure 3). Present is expressed by the absence of head nod. On the other hand, repetition of hand conveys aspect. Single hand movement gives completive while repetitive hand gives incompletive. Table 1 summarizes Gökgöz's proposal for the interpretations of the interaction of tense and aspect in TiD.

Figure 2. Nonmanual marking to express 'future'

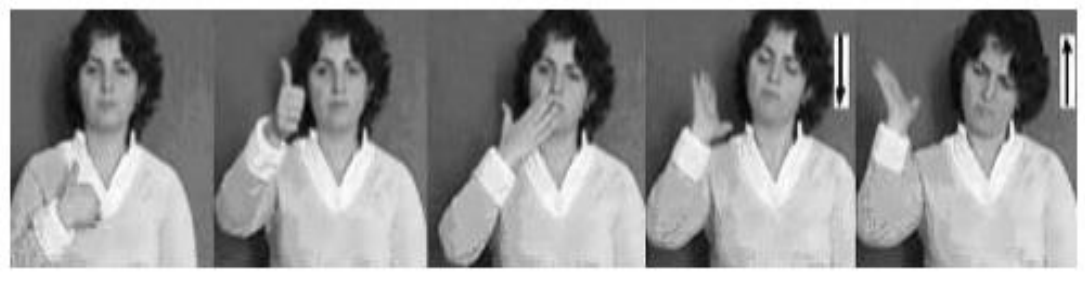

hn

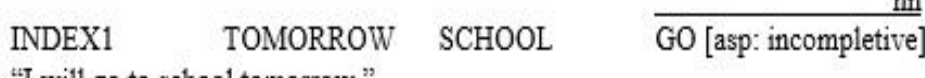

"I will go to school tomorrow." 
Figure 3. Nonmanual marking to express 'past'

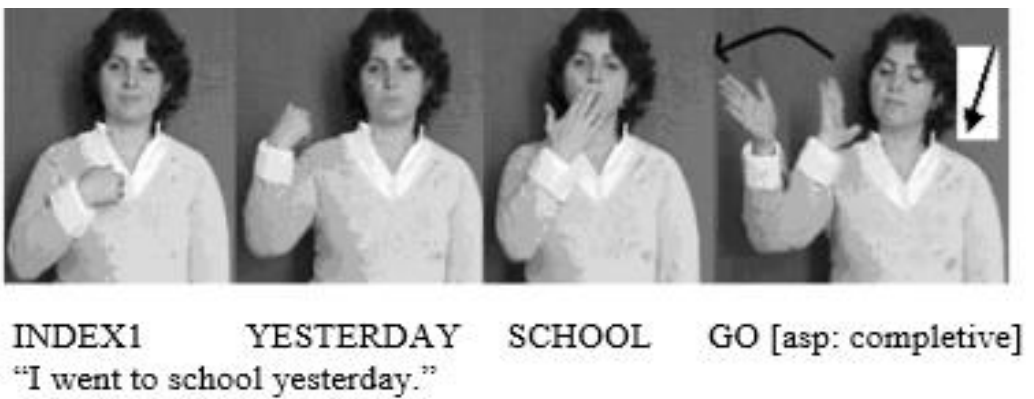

Table 1. Interaction of Tense and Aspect in TiD in Gökgöz (2009, p. 32)

\begin{tabular}{lll} 
Tense & Aspect & Interpretation \\
\hline Single head nod & Single hand movement & Past-Completive \\
\hline Repetitive head nod & Repetitive hand movement & Future-Incompletive \\
& & \\
\hline Absence of head nod & Repetitive hand movement & Present-Incompletive
\end{tabular}

On the other hand, Arik (2012) reports that he did not find a systematic tense marker in TID. Furthermore, the present study will show that head nod does not regularly occur with each verb type and that other strategies more consistently convey tense information suggesting that head nod does not encode tense information.

As the first to examine timelines in TID, Arık (2012) just studied Line 1 according to Sinte's (2013) categories. Dikyuva et al. (2016) also only mentions Line 1 in their book. Arlk (2012) concluded that this line does not always include all time expressions such as days or months in TID thus, this line is not productively used to express temporal relations. One should note that the signs of days and months in TID are mostly body-anchored signs hence their signing space cannot change. However, this study will show that they can be used on other timelines, like Line 2, when co-occurring with pointing signs. Another crucial point is that sign languages may exhibit more than one timeline as Sinte (2003) pointed out. In the following section, I will present my data collection methods. Then, I present how time adverbials and time lines are employed to introduce time information in TİD.

\section{Methodology}

Seven participants (1 male, 6 female), whose ages range from $27-57$ (mean 37,42 ), participated in the study. At the time of data collection, all participants lived in İstanbul and were actively involved in the Deaf community. Two of the 
participants whose ages are 34 and 27 (mean 30,5) acquired TiD from their parents, therefore are native signers. Five whose ages range from 30-57 (mean 40,2) are fluent signers who were exposed to TID before age 11.

For this study, the participants were presented with different sentences which had been recorded with the Deaf interpreter $(n=95)$ and asked what the tense of the sentence was. Some sentences contained overt time adverbials while others had head movement without time adverbials. They were asked to respond by identifying the time of the event as past, present, or future, or by providing an appropriate time adverbial such as NOW, YESTERDAY, or TOMORROW. Additionally, the time adverbials in the sentences were presented in different syntactic positions. Twenty three different verbs in the sentences were chosen from different verb categories - eight agreeing (two backward, six forward agreeing), five spatial, and ten plain verbs to test whether head nod systematically occurs with all of them (see Appendix 2 for the whole list of verbs). Some of the sentences contained perfective markers with verbs since this study was a part of a larger study which mainly focused on those markers thus the total number of sentences is ninety five with different combinations and mini-discourses.

The data were collected using three SONY Handycam cameras, recorded in HD format. In order to capture the nonmanual markers, the data were recorded from three different angles, one capturing the whole scene including the participant and the researcher, the others standing across from the participant.

The collected data were converted to a research friendly format on Adobe Premier CS6 and Media Encoder CS6. For the analysis of nonmanual markers, only the data which were found grammatical by the participants were used. When the participants were shown the sentences, they were also told to judge the sentences in terms of naturalness like place of signs or appearance of nonmanuals with signs. Participants' comments in terms of naturalness were noted by the researcher.

\section{Findings}

Section 3.1 presents what time information is inferred in the sentences where a time adverbial is not present and the head nod accompanies the verb. Briefly, there is not a specific interpretation associated with head nod only, which will be discussed in the section 3.1. Time interpretation becomes clear when there is an overt time adverbial in the sentence or in the discourse, which will be the focus of section 3.2. Further, the section will also present the position in the sentence where a time adverbial occurs. Lastly, section 3.3 will describe another strategy, timelines, to convey time information in TIDD based on Sinte (2013). 


\subsection{Interpretation of Sentences without Time Adverbials}

For the sentences without time adverbials, head nod does not convey the tense of the sentences. There was a wide range of answers regarding the time of the event despite the presence of head nod (cf. Gökgöz, 2009). To illustrate, (1) contains repetitive head nod (rhn) over the verb which is expected to convey future tense according to Gökgöz (2009). However, three of seven participants interpreted the tense of the sentence as past tense and the event completed while four of them interpreted it as present tense. Likewise, three out of seven participants interpreted the event expressed in (2) as a present or a future event while four out of seven interpreted it as a past event although the sentence has a single head nod (shn) over the verb, which is expected to mark the tense of the sentence as past according to Gökgöz (2009). There is no consistency in the interpretation of head nod. These interpretations show that head nod is not the predictor of conveying time information.

(1) DINNER FOR BREAD BUY

rhn

Intended: "I will buy bread for the dinner."

Predicted: Future

Informants' responses: $3 / 7$ past $\&$ completed

4/7 present

(2) $\mathrm{IX}_{1} \overline{\mathrm{TELL}}_{2}$

$$
\text { shn }
$$

Intended: "I told you."

Predicted: past

Informants' responses: $3 / 7$ present or future

$$
\text { 4/7 past }
$$

(3) IX-POSS ${ }_{1}$ FRIEND MANY $_{3}$ MAKE-FUN-OF $_{1}$

Intended: "My friends make fun of me."

Predicted: present

Informants' responses: $3 / 7$ present

4/7not obvious

An observation is that the interpretation of time reference may depend on the telicity of the events. When the event was telic, the participants mostly interpreted the event to have taken place in the (recent) past. Seven out of eleven verbs were interpreted as recent past without a specific time adverbial ${ }^{2}$.

2 GEL 'come' and GiT 'go' are not counted in either telic or atelic categorization since the movement of the sign can be manipulated as in Figure 2 and 3, so they can be interpreted as perfective or imperfective. Without time adverbials, their interpretation was based on the internal movement of the sign. 
On the other hand, when the event was atelic, most of the participants judged the time as present. Seven out of ten verbs were interpreted as present. Sentence (1) containing a telic event was reported to have occurred in the (recent) past while the atelic event in (3) was reported as in the present or as holding for a time like continuous. Many scholars have pointed out the fact that for many sign languages, the default tense interpretation is present when a time adverbial does not occur in the sentence (Cabeza Pereiro \& Fernandez Soneira, 2004; Pfau et al., 2013). However, in these TID examples we see that the telicity of the events may also affect how the time of the sentence is interpreted.

Additionally, corpus data have sentences with imperative structures where head nod occurs over the imperative form of the verb. Imperative structures lack tense phrase, thus head nod should not have occurred with an imperative verb if it was a tense marker. In sentence (4), the interpreter gives instructions to the participant. Instructions are given in imperative forms and head nod occurs over UNDERSTAND, which is unexpected. Moreover, head nod only occurs over UNDERSTAND even though the sentence has three verbs, WATCH, UNDERSTAND, and TELL ${ }^{3}$. To summarize, head nod does not consistently occur with each verb and it may have another function rather than marking tense as seen in (4) (Göksel \& Kelepir, 2013).

(4) ONE ONE ONE WATCH UNDERSTAND ${ }^{\text {hn }}{ }_{1}$ TELL $_{3}$

"Watch (videos) one by one, understand, then tell."

Furthermore, another finding is that the event structure affects the appearance of head nod over the verb. To illustrate, Figures 4 and 5 have the same verb in the future and past contexts. All participants reported that it is difficult to have repetitive head nod over MEET in the future context as in (5) in contrast to $\mathrm{GO}$ as in Figure 3. Even though they are in different contexts, they have the same phonological realizations: a single movement and the change in the palm orientation. If Figure 2 and Figure 3 above are reconsidered, the phonology of the verb GO allows the modification of internal movement of the verb due to the Event Visibility Hypothesis (EVH) (Wilbur, 2009). In other words, GO is an event which has a process and an endpoint. This is visible through the path in the sign and the agreement on the space with the goal which serves as the endpoint. Thus, it is possible to represent GO as a complete process with the endpoint or as an ongoing process without reaching

3 Özsoy et al. (2015) reported various head tilts (forward head tilt, sideward head tilt, or backward head tilt) occurring with commands in TID. In this study, head nod is considered as chin moving down, 'inclined head' rather than moving forward. 
the endpoint. Thanks to EVH, the different representations are phonologically realized differently in sign. The first case is realized as a single path movement whereas the second case is realized as repetitive movement. At this point, the question is whether this difference allows head nod accompanying the movement in the sign. To answer this, we need a verb which has only change of state. For instance, MEET, which is an achievement verb lacks a process and the endpoint is encoded with the change in the palm orientation as seen in Figure 4 and Figure 5. Furthermore, MEET in these figures was represented with different time adverbials YESTERDAY and TOMORROW. Both sentences have single head nod even though the sentences with future time adverbial are expected to occur with repetitive head nod. The point is that the ability to modify the internal movement based on EVH affects the head nods accompanying the verb. However, it is not possible to modify the internal movement of $\mathrm{MEET}^{4}$ in terms of tense due to its event structure, thus it is not possible to have more than one head nod over the verb as seen in (5) in contrast to the verb GO. This observation was asked to participants for other telic verbs and the result holds for them.

Figure 4. Verb MEET in the future context

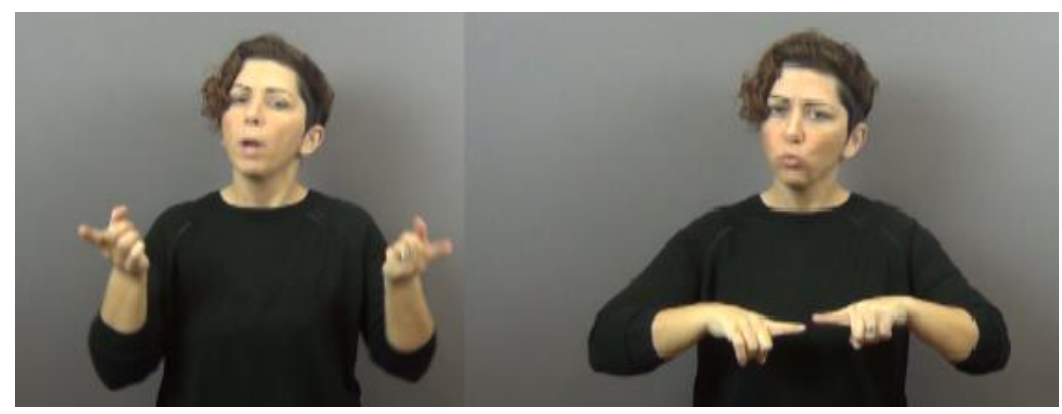

4 Please note that it is possible to have a longer path with MEET to convey that time between beginning and ending of the event is long. Thus, it modifies the runtime rather than the tense information (Wilbur, 2009). 
Figure 5. Verb MEET in the past context

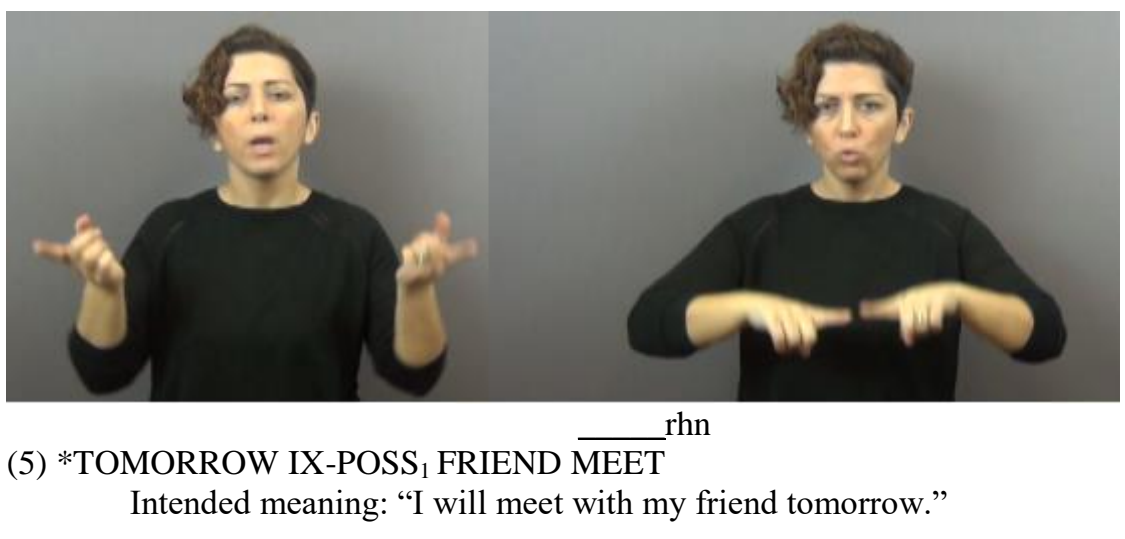

This section has discussed the conclusion that head nod in TiD is not tense marker based on two findings; the interpretations of the sentences without time adverbials and the phonological realizations of the same verb in different time frames. The participants do not have a systematic interpretation for the sentences even though head nod accompanies the verb. Furthermore, it is not possible to have multiple head nods over different verb types due to their phonology which are affected by the event structure as in (5). Lastly, the important observation is that the event structure also affects the interpretation of the default tense. It is interpreted as recent past when the event is telic. On the other hand, it is interpreted as present if the event is atelic. Overall, tense is expressed in the discourse via firstly introducing the time adverbial at the beginning of the discourse, then mentioning the events within this time frame. In addition to event structure, discourse factors also play a role in time interpretation.

\subsection{Time Adverbials in TiD}

Section 3.2.1 will describe the syntactic positions time adverbials appear in TID. Then, building upon the findings in the previous section, how time frame is set out in a mini-discourse will be discussed in Section 3.2.2. Before presenting their syntactic positions and time frame, the properties of time adverbials will be described next.

Adverbials referring to the past are articulated in two ways: The first one is a pointing sign with thumb $b^{5}$ extended pointing to space in the back of the

\footnotetext{
5 The signer in the picture in (6) signs YESTERDAY with ASL A-bar handshape,
} however some signers sign it with the index finger. 
signer as in DÜN 'yesterday' in (6a). The second is a flat hand with a repetitive movement as in ESKIDEN 'in the past' in (6b), whose orientation is backward. In contrast, for future reference which can be seen in (7a), the sign YARIN 'tomorrow' has the same handshape as DÜN 'yesterday' but the sign moves to point to the signer's front. The sign ILERIDE 'in the future' has the same handshape, flat hand as in ESKIDEN 'in the past', as seen in (7b), but moves forward. Cross-linguistically, present time adverbials are articulated by a downward movement immediately in front of the signer (Pfau et al., 2013, p. 189). As seen in (8), BUGÜN 'today' and ŞİMDİ 'now' are consistent with this observation. ŞİMDİ 'now' can also be signed only with the dominant hand.

(6) Time adverbials DÜN 'yesterday' and ESKIDEN 'in the past' referring to the past in TID:
a. YESTERDAY
b. IN THE PAST

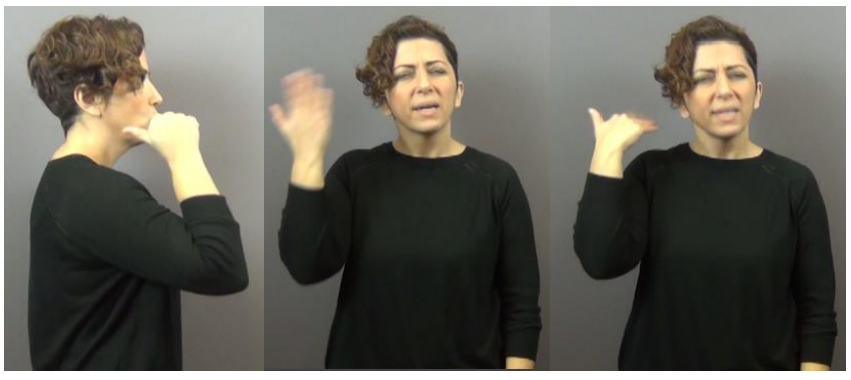

(7) Time adverbials YARIN 'tomorrow' and İLERIDEE 'in the future' referring to the future in TID:

\section{a. TOMORROW}

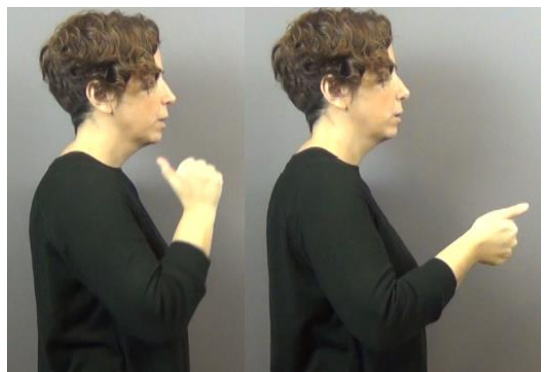




\section{b. IN THE FUTURE}

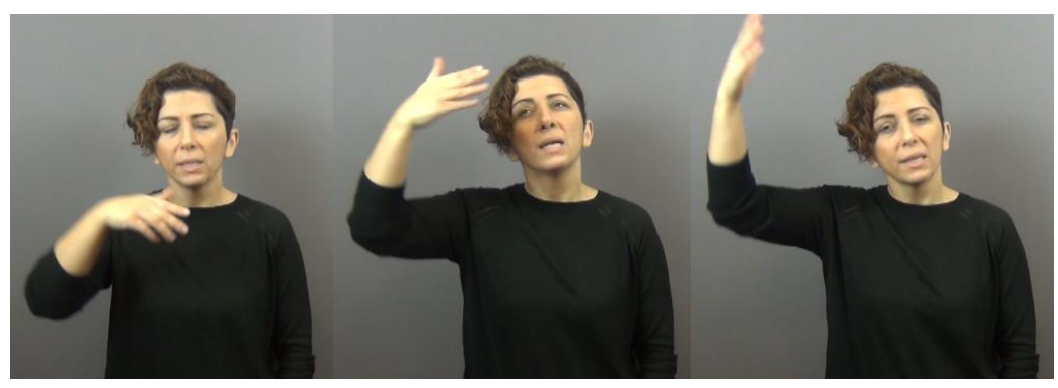

(8) Time adverbials BUGÜN 'today' and ŞİMDİ 'now':

a. TODAY

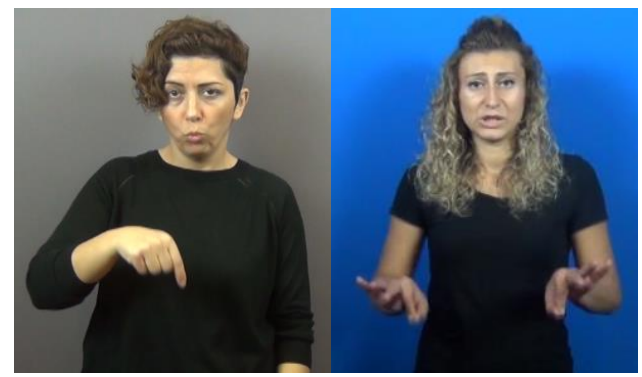

\subsubsection{Syntactic position of time adverbials}

The research question for this subsection is whether there are any restrictions on the distribution of time adverbials in a sentence. Thus, the participants were presented sentences where the time adverbials were located in different positions, namely in sentence initial (9), preverbal (10) and sentence final (11) positions. The participants found (9) and (10) which respectively have sentence initial and preverbal time adverbials grammatical while (11), with a sentence final adverbial, was judged to be ungrammatical. ${ }^{6}$

(9) YESTERDAY IZMIR COME

"Yesterday, I came from Izmir."

(10) IZMIR YESTERDAY COME

"I came from Izmir yesterday."

\footnotetext{
6 Although the sentences do not have any nonmanual marker on the time adverbial, one participant commented that sentence (10) is distinct from (9) in terms of focus. That is the emphasis is on the time adverbial in (9). Focus marking in TiD has not been studied much so far so I will not comment on this any further.
} 
(11) *IZMIR COME YESTERDAY

"I came from Izmir yesterday."

Table 2 presents the participants' judgments for time adverbials in different syntactic positions. The numbers represent the number of participants who judged the sentence as grammatical in ratio to the total number of participants. The time adverbials tested are YESTERDAY, A-LITTLE-WHILE-AGO, LAST-WEEK, TWO^WEEK-AGO, TOMORROW, TWO^WEEK-LATER, TODAY and NOW. As seen in Table 2, all the time adverbials were accepted in both sentence-initial and preverbal positions. In conclusion, time adverbials in TID can occur either in sentence initial or in preverbal position but sentence-final position is not acceptable.

Table 2. The participants' Judgments for Time Adverbials in Different Syntactic Positions

\begin{tabular}{lccc} 
& S-initial & Preverb & S-final \\
\hline YESTERDAY & $7 / 7$ & $7 / 7$ & $2 / 7$ \\
\hline TOMORROW & $7 / 7$ & $7 / 7$ & $1 / 7$ \\
\hline A-LITTLE-WHILE-AGO & $7 / 7$ & $7 / 7$ & $0 / 7$ \\
\hline TODAY & $7 / 7$ & $7 / 7$ & $2 / 7$ \\
\hline LAST-WEEK & $7 / 7$ & $7 / 7$ & $1 / 7$ \\
\hline NOW & $7 / 7$ & $7 / 7$ & $3 / 7$ \\
\hline TWO $^{\wedge}$ WEEK-AGO & $7 / 7$ & $7 / 7$ & $0 / 7$ \\
\hline TWO $^{\wedge}$ WEEK-LATER & $7 / 7$ & $7 / 7$ & $0 / 7$
\end{tabular}

\subsubsection{Time interpretation in the discourse}

Findings on other sign languages show that time adverbials set the time frame for the events and all the events are interpreted with respect to this time frame unless a new time adverbial is introduced, which is similar to other sign languages as reported in Cabeza Pereiro and Fernandez Soneira (2004), Pfau et al. (2013) and Quer et al. (2017). To illustrate, (12a) and (12b) in TID have a time adverbial introduced sentence initially; there is no other time adverbial in the following sentence ASSIGNMENT ${ }_{1}$ GIVE FORGET. On the other hand, a time adverbial is introduced after the matrix verb in $(12 \mathrm{c})$; the sentence is interpreted differently.

(12) a. YESTERDAY REMEMBER ASSIGMENT ${ }_{1}$ GIVE FORGET

"Yesterday, I remembered. I had forgotten to give the assignment."

b. NOW REMEMBER ASSIGMENT ${ }_{1}$ GIVE FORGET

"Now, I have remembered. I forgot to give assignment. 
c. REMEMBER YESTERDAY ASSIGNMENT ${ }_{1}$ GIVE FORGET

(i) "I have remembered. I forgot to give the assignment yesterday."

(ii) *"I remembered yesterday. I forgot to give the assignment."

As seen in (12), all the events (remembering, forgetting and giving) are interpreted to have taken place in the time set by the time adverbials. In other words, all the events are interpreted to have happened YESTERDAY in (12a) while in (12b), they are interpreted to have taken place in the recent past as in "I have remembered". On the other hand, the participants interpreted REMEMBER in (12c) to have taken place in recent past while FORGET and GIVE to have taken place YESTERDAY although there is no time adverbial in sentence initial-position. The interpretation in (12c-ii) is not possible. The interpretation of (12c) is similar to (12b), but the only difference is that in (12c) the event time of 'forget' is overtly expressed while the event time of 'remember' in (12c) is not known. These are actually consistent with (11). Since YESTERDAY cannot be sentence final, it cannot be interpreted as belonging to the first sentence. To summarize, time adverbial sets the time frame for the sentence in which the event occurs.

Example (13) is another example for time adverbials. It has two different time adverbials NOW and LATER. The first one is introduced at the beginning of the sentence and it is not changed until the third sentence where the second adverbial is introduced. Tense of the first two sentences is interpreted as present while the tense of the last sentence is interpreted as future. Furthermore, head nod in the first sentence does not appear on the verb, which should have if it was a tense marker. On the contrary, it appears on TWO and marks the sentence boundary (Göksel \& Kelepir, 2013). Based on this, the following question is why head nod does not appear in the third sentence if it marks clause boundary. This question will be left for future studies.

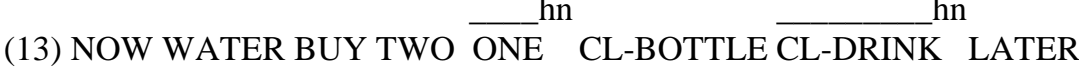 ONE CL-BOTTLE}

"Now, I have bought two bottles water. I drink one now and the other one later."

The mini discourse in (14) has also a single time adverbial YESTERDAY and all events in the discourse (walk, see, call) are interpreted in the past. Another interesting point in this discourse is that it has an imperfective event in the past. The event 'walk' is imperfective because it is interrupted with another event, an accident, which can be inferred from the context. If Table 1 is recalled, the expectation for the signs WALK, SEE, CALL is repetitive hand movement with Table 1 a single head nod (shn) at the end of repetitive hand 
movement (c.f. Gökgöz, 2009). However, in sentence (14), these signs have single path movement. As one can see in (14) the verb is signed with head forward (hf) and eyebrow raising (er) instead of head nod. Head nod is also not present on the verbs SEE and CALL even though the time of both events is past. Please note that the signer has head forward over WALK and she continues signing with head forward until IMMEDIATELY. Head forward becomes more intensified on SEE, where it is difficult to distinguish it from head nod. Head forward is considered as head's movement from neck to onwards while head nod is considered as inclined head. Even if head forward on SEE is considered as head nod, then the question is why it does not appear with other verbs when their tense is set as past with the adverbial YESTERDAY. Moreover, when the participants were asked whether single head nod at the end of the repetitive hand movement of WALK is acceptable in this context, they responded that head nod should accompany the movement in the hand or it should be like the one in (14) ${ }^{7}$. The interpretation for tense of these events (walk, see, call) is past tense due to time adverbial YESTERDAY. The interpretations for aspect of these events are various because they denote different event types. WALK is interpreted as imperfective while SEE and CALL are interpreted as perfective.

es

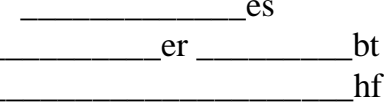

hf

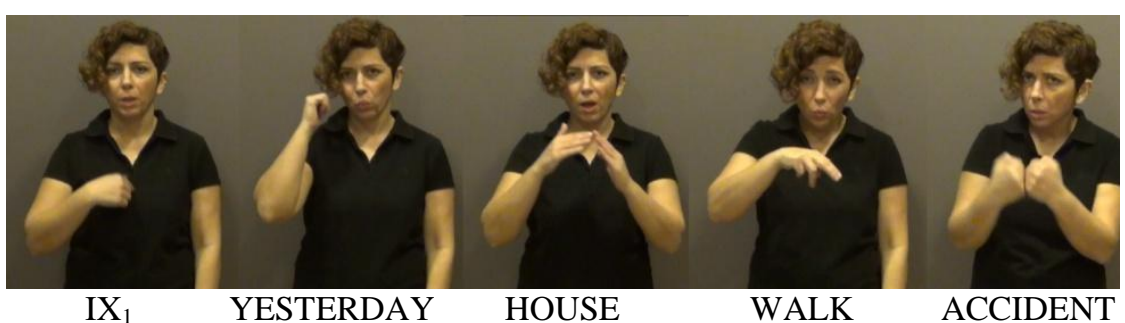

7 Abbreviations used for nonmanuals in this example are: es - eye squint, er- eyebrow raise, bt -- body turn, hf - head forward, shn - single head nod, htr - head tilt right. 


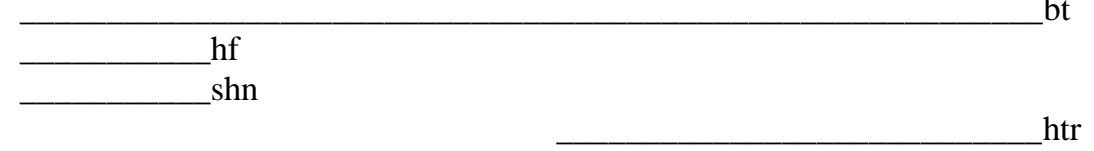

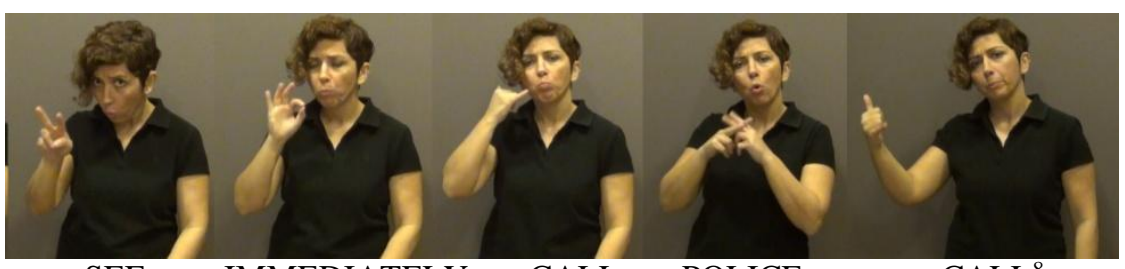

SEE

IMMEDIATELY

CALL

POLICE

$\mathrm{CALL}^{8}$

"Yesterday, I was walking home, saw an accident, immediately called the police."

As a summary, time information is overtly conveyed by time adverbials in TID contrary to Gökgöz's (2009) claim that nonmanual marker, namely head nod can be one of the strategies to express tense. In the absence of a time adverbial, the default tense is interpreted as present with atelic events (7/10), and (recent) past with telic events (7/10). Another finding is that the time frame which is set by a time adverbial in the context is true for all the events until a new time adverbial is introduced as seen in (13).

\subsection{Timelines in TID}

While examining time adverbials, their placement in the signing space has appeared with a path movement, which yields timelines (Arık, 2012; Cabeza Pereire \& Fernandez Soneria, 2004; Cogen, 1977; Pfau et al., 2013; Sinte, 2013). This section will describe the timelines observed in the data.

Time adverbials mentioned in section 3.2 are pointing signs and they point to the back, front, or the side of the signer depending on the time reference. Briefly, the adverbials referring to the past in (15) are oriented towards the space behind the signer, the back of the timeline. On the other hand, the time adverbials referring to the future in (16) are oriented towards the signer's front, in a sense, the front of the timeline. This line which is the most

8 Sentence (14) can be an example for other phenomena like head tilt right over CALL which is in the same direction of the path of CALL that is an agreeing verb. It may mark agreement, yet the detailed study is needed before arriving a conclusion. Moreover, the verb CALL is doubled in this example, which is a rare case in SOV sign language. I do not have enough support even to speculate a possible explanation for this, which will be also left for future studies. 
frequently observed one across sign languages is referred to as Line 1 in Sinte's (2013) categorization.

(15) Time adverbials ESKIDEN 'in the past' and ÇOK ESKIDEN 'in the distant past', respectively:

a. ESKIDEN 'in the past'

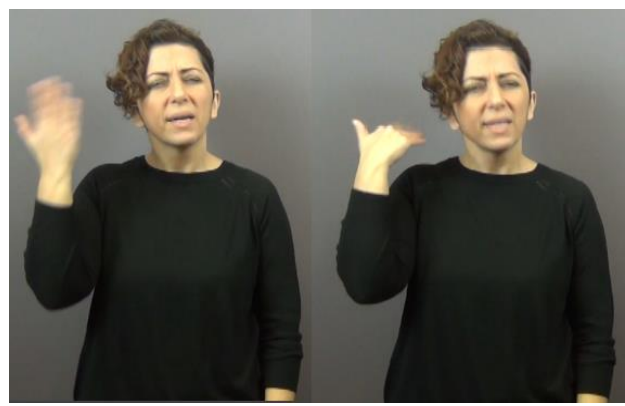

b. ÇOK ESKIDEN 'in the distant past'

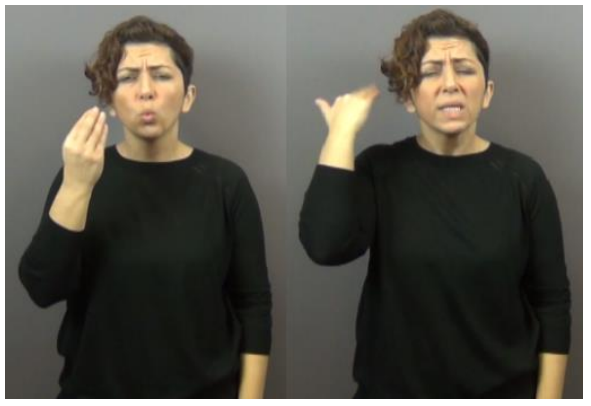

(16) Time adverbials İLERIDE 'in the future' and ÇOK İLERIDE 'in the distant future' respectively:

a. İLERIDE 'in the future'

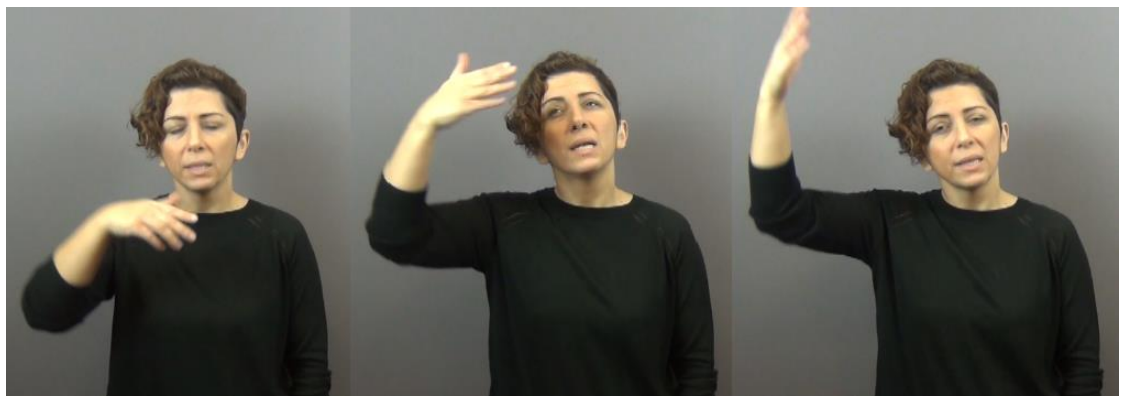


b. ÇOK İLERIDE 'in the distant future'

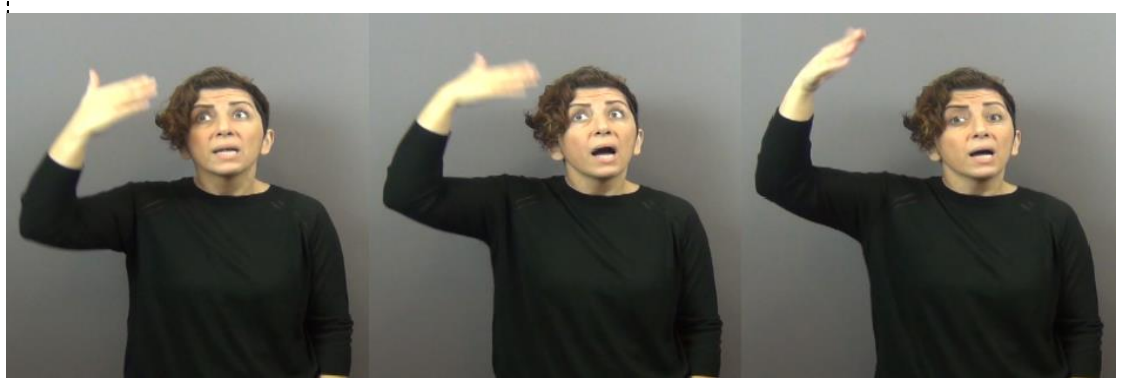

Comparing two time adverbials, in the articulation of ESKIDEN 'in the past' (15a) eyebrow frowning gets intensified and during the squint, the signer's eyes are almost closed in the distant past (15b). On the other hand, in (16a) eyebrows are raised more and eyes are wide open in the distant future (16b). Researchers also highlight that the length of path movement correlates with the distance between the times of the events (Cabeza Pereiro \& Fernandez Soneira, 2004; Cogen, 1977; Pfau et al., 2013; Sinte, 2013). Regarding this, Wilbur (2008) names this extension as extra, which has meaning of 'extra, more of'. This simultaneous suffix is realized as an arc movement (p. 235). With regard to time adverbials, if the time reference is near future, the time adverbial is signed close to the body; on the other hand, if the time reference is distant future, the adverbial is signed far from the body. Namely, the path is extended for distant meaning.

As for TiD, in addition to the lengthening of the path, the intensity of the nonmanuals is also changed as shown in the contrast between (15a) and (15b), and between (16a) and (16b). For other sign languages, there has been no mention of nonmanuals for near and distant distinction. Interestingly, the nonmanuals for distant past and distant future are the same as the ones for comparative structures. Both pairs of nonmanuals namely eyebrow raising and eye opening, and eyebrow lowering and eye squint have been observed for the comparative structures in TíD (Kaşıkara, Özsoy, \& TamyürekÖzparlak, 2015; Özsoy \& Kaşıkara, in press). Kaşıkara et al. (2015) observed that eyebrow raising and eye opening are seen with MORE constructions while eyebrow lowering and eye squint are attested with LESS constructions. Moreover, in addition to LESS constructions, eyebrow lowering and eye squint occur with MORE constructions which make a comparison of adjectives with negative connotations like BAD and WORSE or ROTTEN and MORE-ROTTEN. In addition to negative connotations, they can also accompany the structures such as MORE SMALL or MORE TINY. Near or distant past and future are in a sense making a comparison between the notions near and distant. This may be why these nonmanuals appear with the 
path. The similarity is worth paying attention to, however, further research is needed to make such a proposal.

Timelines can be frozen in the movement of a lexical sign as well. The verb TRANSFER in Figure 6 is signed starting from the signer's shoulder to the front on the dominant side while the signer talks about cultural heritage. The movement in the sign corresponds to the path of Line 1. One can infer that this area in the signing space may have a semantic connection with time and the signer signs the verb or the time adverbial like YESTERDAY or TOMORROW in this space as long as the phonology of a sign can be manipulated.

Figure 6. Signing TRANSFER using Line 1

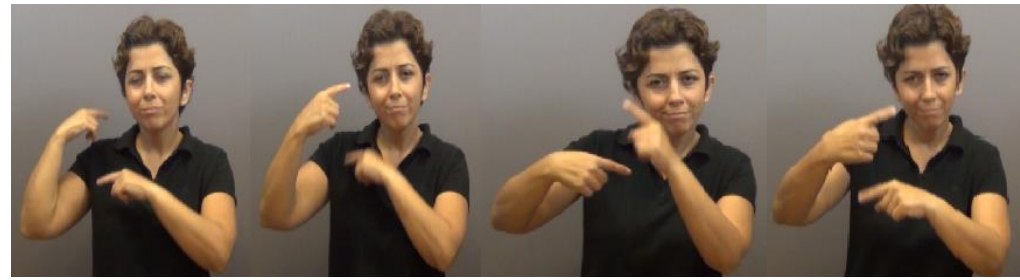

Another example for frozen timelines is the signs LIVE and GROW ${ }^{9}$ as seen in Figure 7 and Figure 8, respectively. Line 6 is realized as the path movement of the lexical sign. The line is realized via the movement from bottom upwards, which can be considered as iconically representing the growth in body and getting tall.

Figure 7. Sign LIVE with Line 6

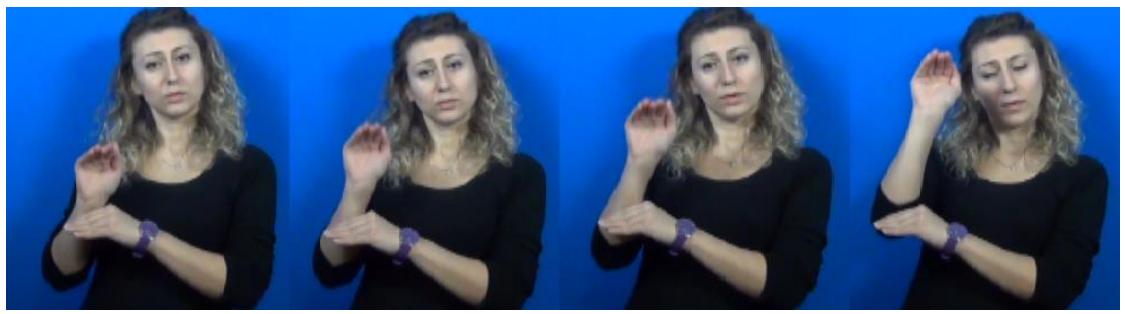

9 The sign GROW is taken from the contemporary Turkish Sign Language dictionary (Makaroğlu \& Dikyuva, 2017). 
Figure 8. Sign GROW with Line 6

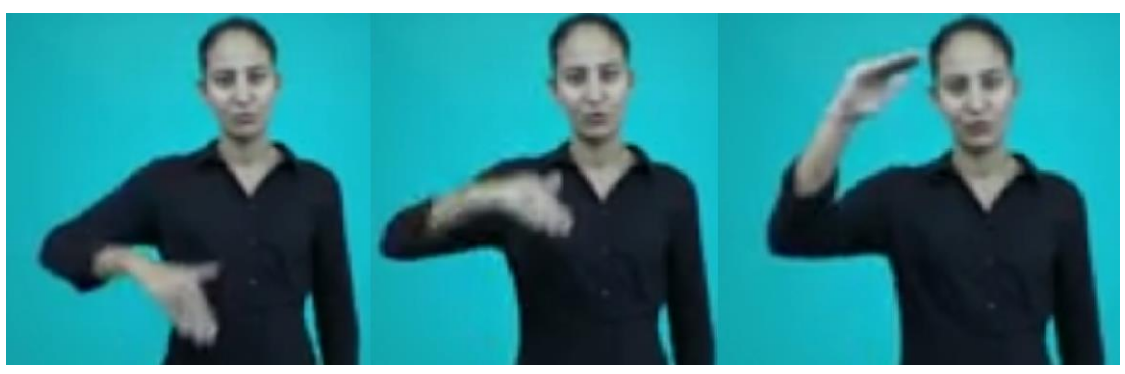

Timeline 2 is oriented from left to right and is used to situate events relative to a reference point or a time span between two reference points. The nondominant hand mostly locates the reference time in the signing space with a pointing sign whose handshape can be either the index finger or ASL-B (b) handshape (from Kubus 2008, p.157).

This is not the handshape of the frequently observed pointing sign, which is the index sign, however, in these examples it stands for a specific time expressed in the utterance such as MEAL (17). In a sense, it assigns a place in the signing space for the time reference for MEAL. Thus, it can be considered as a pointing sign. The time span is signed via the dominant hand which moves either to or from the reference point. For example, consider the second set of stills in (17). There are two different time periods 'BEFORE MEAL' and 'AFTER MEAL'. As you can see, the signer signs these periods according to the reference point 'MEAL': she first signs the reference point MEAL and then uses Line 2 and locates BEFORE to its left and AFTER to its right. The non-dominant hand stands for MEAL and behaves as a pointing sign.

(17) "What should the child in the picture do before and after the meal?"

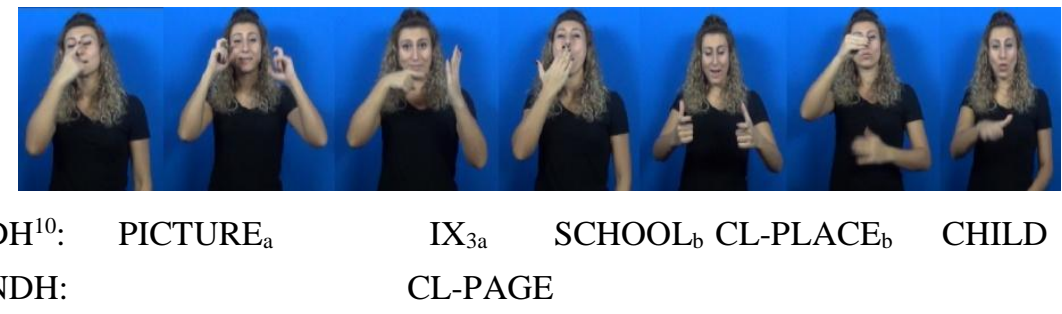

$10 \mathrm{DH}$ is the abbreviation of dominant hand while NDH is the abbreviation of nondominant hand. 


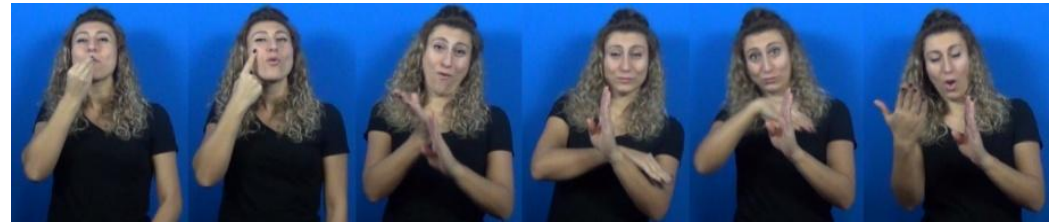

DH: $\mathrm{MEAL}_{\mathrm{c}}$ ACCORDING

NDH:

BEFORE

AFTER

DH: WHAT DO NECESSARY ${ }^{11}$

Sentence (18) is an example of path movement referring to a time span. While signing 'AFTER MARCH', the signer first signs MARCH then places it in the signing space via an index sign on the nondominant hand, and then signs the path movement from the index to an arbitrary point in space.

(18) "After March, the project will go on."

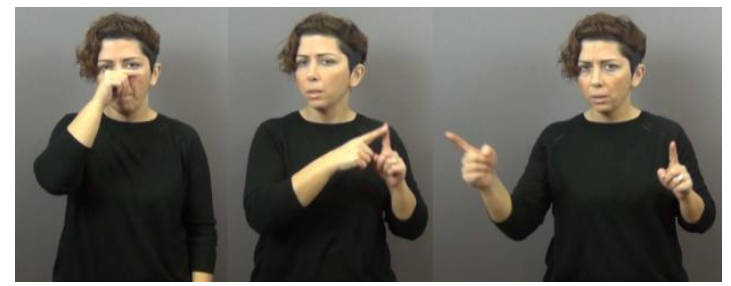

DH:

$\mathrm{MARCH}_{\mathrm{A}}$

${ }_{\mathrm{A}} \mathrm{IX}$

NDH:

${ }_{\mathrm{A}} \mathrm{IX}_{\mathrm{B}}$

The path movement usually is straight as in (18); however, it can also be an arc movement on the coronal plane when the sign of the reference point interferes with the path. In the example (19), the signer signs both of the boundaries of the time span; the left boundary NOW and the right boundary MARCH while she only signs the left boundary of the time span MARCH in (19).

11 LAZIM means necessary and is one of signs which convey modality meaning. For further information, the reader is referred to Özkul (2016). 
(19) "Until March, the project will go on."

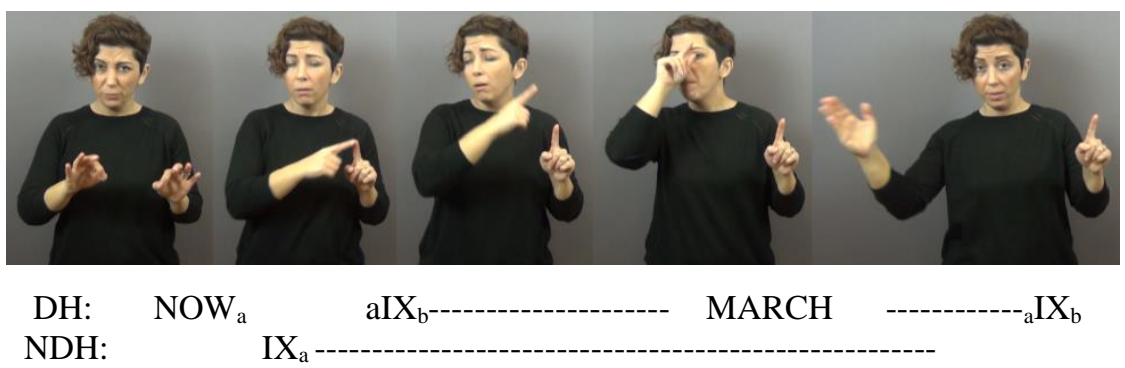

Another difference between (18) and (19) is that the path movement is an arc movement due to the place of the sign MARCH and more interestingly, the sign of MARCH splits the path which the time span forms. The signer signs the path from the index sign until the signing location of the sign MARCH, namely her nose, signs MARCH, and then completes signing the path ${ }^{12}$. As can be observed in the picture (19), she also changes the handshape. The sign starts with the index finger selected and extended and ends with ASL-B (B) handshape, which will be left to further studies and discussions in terms of the morphology.

The same handshape has been also observed in sentence (20). Differently from (19), the handshape was changed to ASL-B (B) after the timeline is signed and ASL-B (B) seems to signal the boundaries of the event 'living'. ASL-B (B) is also the handshape in sentence (21) in a different timeline, Line 4 in Sinte's (2013) classification. Sinte (2013) noted that Line 4 is blending of Line 1, 2 and 3; used for the events in near future. The utterance time in sentence (21) is the first week or days of July and the event time is the end of July, which is near future.

(20) "Atatürk lived between 1881 and 1938."

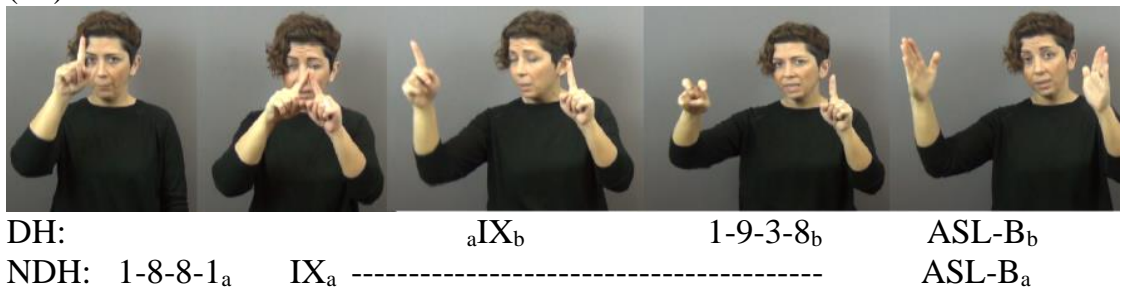

12 To test whether this interruption is seen with other signs whose location is face, similar sentence is asked with different months like FEBRUARY or APRIL. This interruption has not been observed consistently each time however, sentence (19) was asked to another signer and was found acceptable. This interruption needs further study. 
(21) "I will come at the end of July"

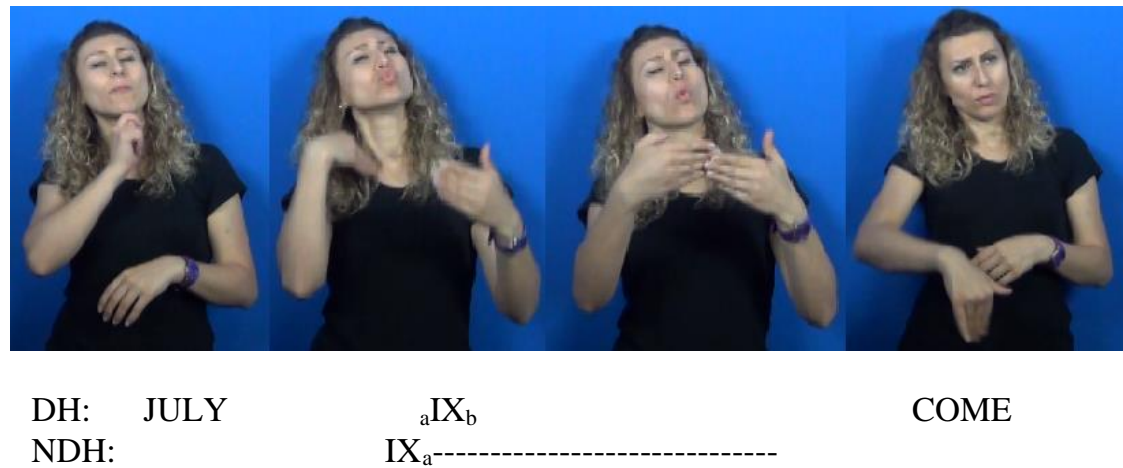

Regarding ASL-B (B) handshape in sentences (17) and (19), it has two distinct usages in these examples. In (17), it entails time reference without specifying both boundaries of the time span. The information conveyed in (17) is only their relation with each other; before lunch, lunch, after lunch. Furthermore, time difference in this ordering is relatively short. In other words, washing hands happens just before or just after lunch. In that case, ASL-B (B) handshape may be used to zoom in the short time difference whereas pointing is used to zoom out and give a bigger perspective to temporal features. On the other hand, in (19), the right boundary of the time span, MARCH is marked with ASL-B (B) handshape, which is a totally different usage than the one in (17). Another function of the ASL-B (B) handshape can be to mark the endpoint of the event. In this example, the right boundary of the time span also corresponds to the deadline of the project. Whether these semantic differences between these two handshapes are systematic needs to be investigated in further studies. ${ }^{13}$

As for days and months in TiD, Arrk (2012) pointed out that they do not occur in Line 1, thus he concluded that temporal space and signing space in TID do not correspond every time. However, the timelines in (18) and (19) show that information about months can be localized at the beginning or at the end of the path via pointing signs. In this sense, Sinte (2013) noted that timelines can be used for different purposes. In other words, Line 1 in TiD seems to give general information about how past, present and future are viewed. On the other hand, Line 2 in TID is exploited to convey a time span between two reference points.

Another case where the path is an arc movement is the one with the time span involving a time of a day such as 'morning', 'noon' and 'evening'. This is

13 I want to thank the reviewer who brought these points into my attention. 
the combination of Line 2 and Line 6 in Sinte's (2013) classification. Line 2 lies parallel to and in front of the signer, and is used to sequence the events while Line 6 is vertical and lies on the dominant side of the signer, and is mostly seen with lexical signs. For instance, the movement of the sign GROW is vertical and the hand moves from neutral space upwards. Pfau et al. (2013) cite Marsaja (2008) where it is reported that the signers of Desa Kolok, a sign language spoken in a village located close to the equator, use Line 6 and the upwards pointing refers to NOON.

As for TID, once times of a day are mentioned in a sentence lexically, MORNING is located at the contralateral low with pointing, NOON is located to the upper mid of the signing space, and EVENING is located in the ipsilateral low, which forms a clockwise movement (22). In TID, the placement of the times of a day in the signing space creates a clockwise timeline which is the combination of Line 2 and 6 . The following sentences are examples of the arc movement referring to the times of a day. The movement in (22) starts from the contralateral side where the reference for MORNING is located and ends where NOON is signed. In contrast to (19), NOON does not split the path even though both MARCH and NOON are signed on the face. While the movement ends in upper mid in (22), in (23) it continues to the ipsilateral side and moves downward. This, in a sense, reflects the movement of the sun from sunrise to sunset. Additionally, in (23), the movement of EVENING assimilates to the arc movement. The sentence in (23) is another example of the signs FROM MORNING TO EVENING where the internal movement of the sign changes and it incorporates the movement path of the timeline.

(22) "I waited for the bus from morning until noon."

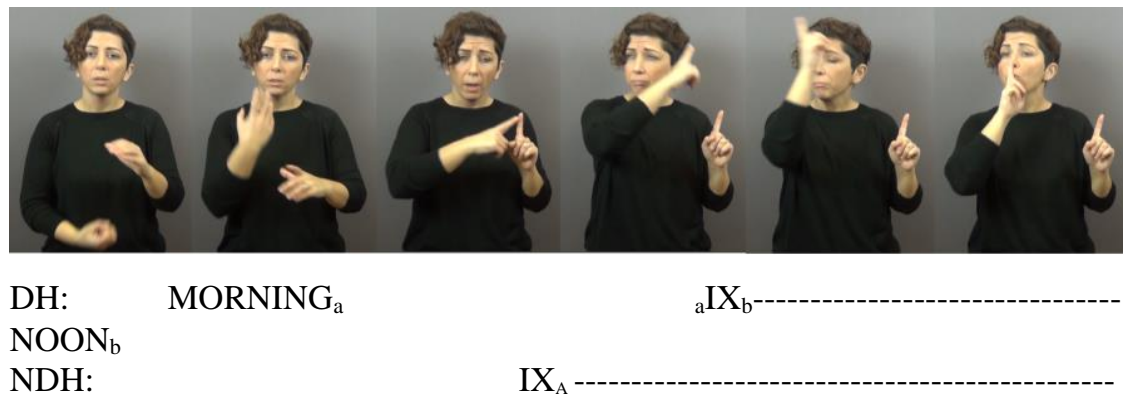


(23) "I need to study from morning till evening."
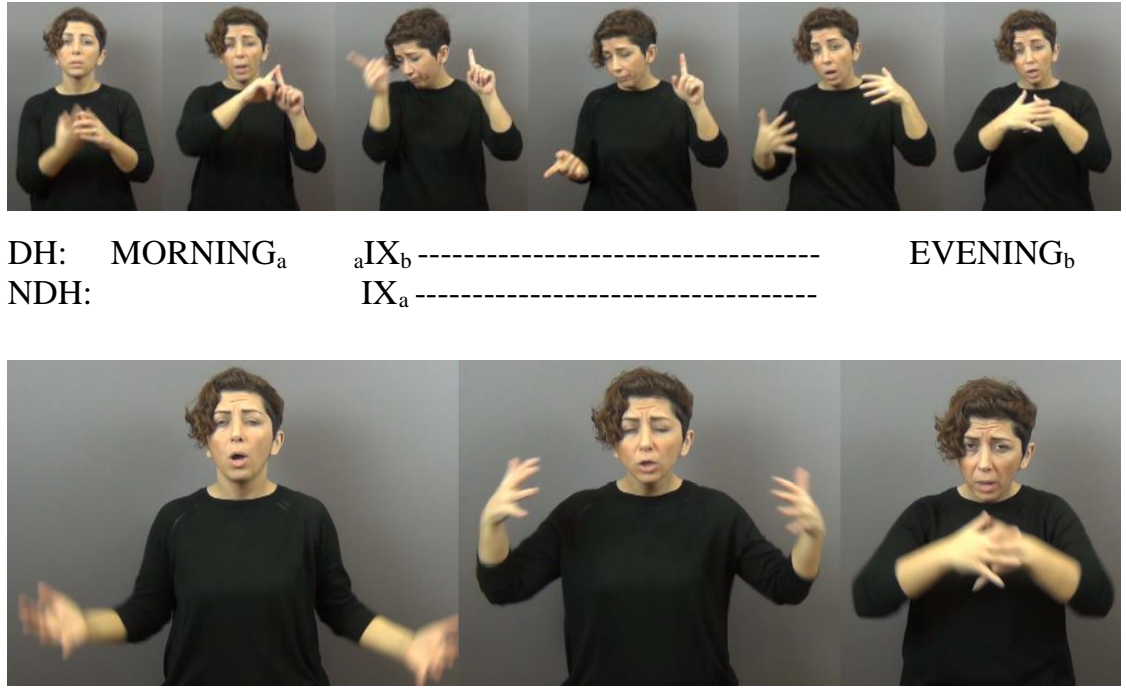

FROM MORNING TILL EVENING

As seen in the examples in (22) and (23), timelines can be combined to convey different time spans. Another complex timeline observed in TID is the combination of Line 1 and Line 2. The line in (24) which means FORYEARS is actually a circular movement rather than an arc movement. It starts from the signer's front and ends again in the front with a contact to the index finger on the non-dominant hand in the neutral space. It is used to talk about a person's life.

(24) "For years, Atatürk served for his country."

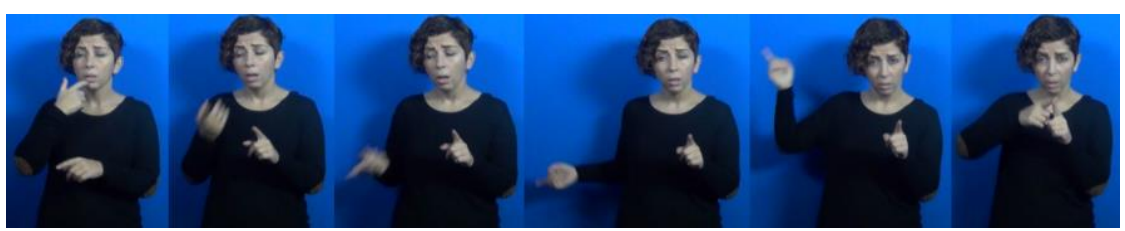

DH: $\quad$ YEAR $_{\mathrm{a}}$

NDH:

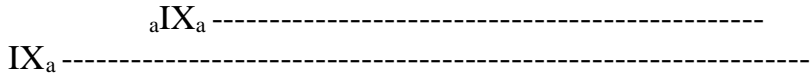

In this section, I described a number of timelines in TID which are used for referring to past and future time spans. IN THE PAST and IN THE FUTURE signs have the same handshape, yet they move in different directions. The first has a backward movement above the signer's shoulder while the latter has 
a forward path in front of the signer. Time spans are signed with a path movement which has index signs for the right and left boundaries of the span. The movement path also becomes an arc movement. The paths defined in the literature, Line 1 and Line 2 according to Sinte (2013), as seen in (24), can be combined and form a new line. Moreover, timelines can be observed in lexical signs such as GROW, which shows Line 6.

\section{Conclusion}

Time information in TID is not encoded as a verbal inflection in every sentence as seen by the fact that head nod does not systematically accompany each verb (contra Gökgöz, 2009). If the verbs COME and MEET are reconsidered, the event structure of those verbs reflect into their phonology (Wilbur, 2009). Thus, head nod cannot occur independently from the internal movement of the verb. Furthermore, Göksel and Kelepir (2013) note that head nod may be a prosodic marker. Thus, bearing in mind that TID is a SOV language (Sevinç, 2006) head nod may have a different function at the end of the sentence and may just happen to cooccur with the verb.

As long as the event structure allows, head nod may be manipulated based on the syllables in the verb. More clearly, syllable structure in sign languages is defined based on the movement of the sign (Brentari, 1998). It has been shown that the multiple head nods are not possible with single path, which corresponds to single movement from one point in the space to another point. Single head nod is possible with single movement on which condition the sign is considered as monosyllabic. On the other hand, repetitive head nod appears with repetitive movement where the sign is not monosyllabic (Wilbur, 2009). Thus, head nod cannot be separated and manipulated differently from the movement of the sign.

Instead, time of the sentence becomes obvious with a time adverbial. Otherwise, the sentence is interpreted as being in the default tense which is present with atelic verbs and recent past with telic verbs unless the sentence has a time adverbial. Time adverbials set the time frame and until the adverbial is changed all events are interpreted in this frame, as discussed for other sign languages (Cabeza et al., 2004).

Another goal of this study was to describe the timelines in TID. Based on Sinte's (2013) study, six different timelines have been observed: Line 1, Line 2 , Line 4 , Line 6 , the combination of Line 2 and 6 , and the combination of Line 1 and 2. Line 1 is the one that has been observed frequently in sign languages and which Arık (2012), and Dikyuva et al. (2016) mention in their studies. It lays over the signer's shoulder on the dominant side. The back of the signer represents the past while the front represents the future. Line 2 lays in front of the signer from the nondominant side to the dominant side. Line 6 
occurs as a vertical line in the dominant side. The complex timelines are the combination of those lines.

It has also been shown that timelines can be either frozen in the lexical signs or formed by the placement of the reference points. The path movement between those points conveys the time span. Alternatively, the internal movement of the lexical sign can be manipulated to convey the time span as in the case of the movement of EVENING turning into an arc movement to convey FROM MORNING TO EVENING.

Time in TID is realized via time adverbials and TID does not inflect individual verbs for tense, which makes it a morphologically tenseless language. Thanks to the visual modality, the realization and the placement of time adverbials may result in timelines and different kinds of time spans which are conveyed in different timelines. They can be frozen into the sign or be realized via pointing signs and path movement during signing.

\section{References}

Arık, E. (2012). Space, time, and iconicity in Turkish Sign Language (TID). A Journal of Humanities and Social Sciences, 4(16), 345-358.

Binnick, R. (1991). Time and the Verb: A Guide to Tense and Aspect. New York: Oxford University Press.

Brentari, D. (1998). A Prosodic Model of Sign Language Phonology. Cambridge: MIT Press.

Cabeza Pereiro, C., \& Fernandez Soneira, A. (2004). The expression of time in Spanish Sign Language (LSE). Sign Language \& Linguistics, 7(1), 63-82.

Clark, H. H. (1973). Space, time, semantics, and the child. In T. Moore, Cognitive development and the acquisition of language (pp. 27-63). New York: Academic Press.

Cogen, C. (1977). On three aspects of time expression in American Sign Language. In L. Friedman, On the other hand: New Perspectives on American Sign Language (pp. 197-214). New York: Academic Press.

Dikyuva, H., Makaroğlu, B., \& Arık, E. (2015). Türk Işsaret Dili Dilbilgisi Kitabı. Ankara: İmpedus Medya Prodüksiyon Ltd. Şti.

Gökgöz, K. (2009). Topics in Turkish Sign Language (TID) Syntax: Verb Movement, Negation and Clausal Architecture. İstanbul: Boğaziçi University; MA Thesis.

Göksel, A., \& Kelepir, M. (2013). The phonological and semantic bifurcation of the functions of an articulator: HEAD in questions in Turkish Sign Language. Sign Language \& Linguistics, 16(1), 1-30.

Göksel, A., \& Kelepir, M. (2016). Observations on clausal complementation in Turkish Sign Language (TID). In A. Herrmann, R. Pfau, \& M. Steinbach, A Matter of Complexity: Subordination in Sign Languages (pp. 65-94). Berlin: Mouton de Gruyter.

Jacobowitz, L., \& Stokoe, W. (1988). Signs of tense in ASL verbs. Sign Language Studies, 331-339. 
Kaşıkara, H., Özsoy, S., \& Tamyürek Özparlak, E. (2015). 'Backward Agreement' in Turkish Sign Language Comparatives, Is it agreement directionality, or gestural? Formal and Experimental Advances in Sign Language Theory. Barcelona: Pompeu Fabra University.

Kubus, O. (2008). An Analysis of Turkish Sign Language (TID) Phonology and Morphology. Ankara: METU: MA Thesis.

Le Guen, O. (2012). An exploration in the domain of time: From Yucatec Maya time gestures to Yucatec Maya Sign Language time signs. In U. Zeshan, \& C. de Vos, Sign languages in village communities: Anthropological and linguistic insights (pp. 209-249). Nijmegen: Ishara Press.

Makaroğlu, B., \& Dikyuva, H. (2017, May). (Turkish Ministry of Family and Social Policy) Retrieved March 27, 2018, from The Contemporary Turkish Sign Language Dictionary: http://tidsozluk.net.

Meir, I., \& Sandler, W. (2008). Tenses and aspects. In I. Meir, \& W. Sandler, A language in space: The story of Israeli Sign Language (pp. 89-106). New York: Lawrence Erlbaum Associates.

Özkul, A. (2016). Deontic and Epistemic Necessity in Turkish Sign Language (TID). Unpublished manuscript.

Özsoy, S. A., Kelepir, M., Nubalaoğlu, D., \& Hakgüder, E. (2015). Commands in Turkish Sign Language. Gengo Kenkyu, 1-18.

Özsoy, S., \& Kaşıkara, H. (in press). Comparatives in Turkish Sign Language (TID). In K. Wotjylak, Y. Treis, \& L. de Vreis, Comparative Constructions. Free University of Amsterdam.

Özyürek, A., \& Perniss, P. (2011). Event represantations in signed languages. In J. Bohnemeyer, \& E. Pederson, Event represantations in language and cognition (pp. 84-107). New York: Cambridge University Press.

Pfau, R., Steinbach, M., \& Woll, B. (2013). Tense, aspect and modality. In R. Pfau, M. Steinbach, \& B. Woll, Sign Language. An international handbook (HSK Handbooks of linguistics and communication sciences) (pp. 186-204). Berlin: Mouton de Gruyter.

Quer, J., Cecchetto, C., Donati, C., Geraci, C., Kelepir, M., Pfau, R., \& Steinbach, M. (2017). SignGram Blueprint: A guide to sign language grammar writing. De Gruyter Reference.

Sevinç, A. M. (2006). Grammatical Relations and Word Order in Turkish Sign Language (TID). METU: Unpublished MA Thesis.

Sinte, A. (2013). Expression of time in French Belgian Sign Language (LFSB). In L. Meurant, Sign language research, uses and practices (pp. 205-235). Berlin: Mouton de Gruyter.

Sutton-Spence, R., \& Woll, B. (1999). The Lingusitics of British Sign Language. An Introduction. Cambridge: Cambridge University Press.

Wibur, R. B. (2008). Complex predicated involving events, time and aspect: Is this why sign languages look so similar? In J. Quer, Signs of the time: Selected papers from TISLR 2004 (pp. 217-250). Hamburg: Signum Press.

Wilbur, R. (2009). Productive reduplication in a fundamentally monosyllabic language. Language Sciences, 31(2), 325-342. 
Zeshan, U. (2002). Sign language in Turkey: The story of a hidden language. Turkic Languages, 6, 229-274.

Zeshan, U. (2003). Aspects of Türk İşaret Dili (Turkish Sign Language). Sign Language \& Linguistics, 6(1), 43-75.

Zucchi, S. (2006). Along the time line: Tense and time adverbials in Italian Sign Language. Natural Language Semantics, 99-139. 


\section{Appendix 1: Timelines in TİD}

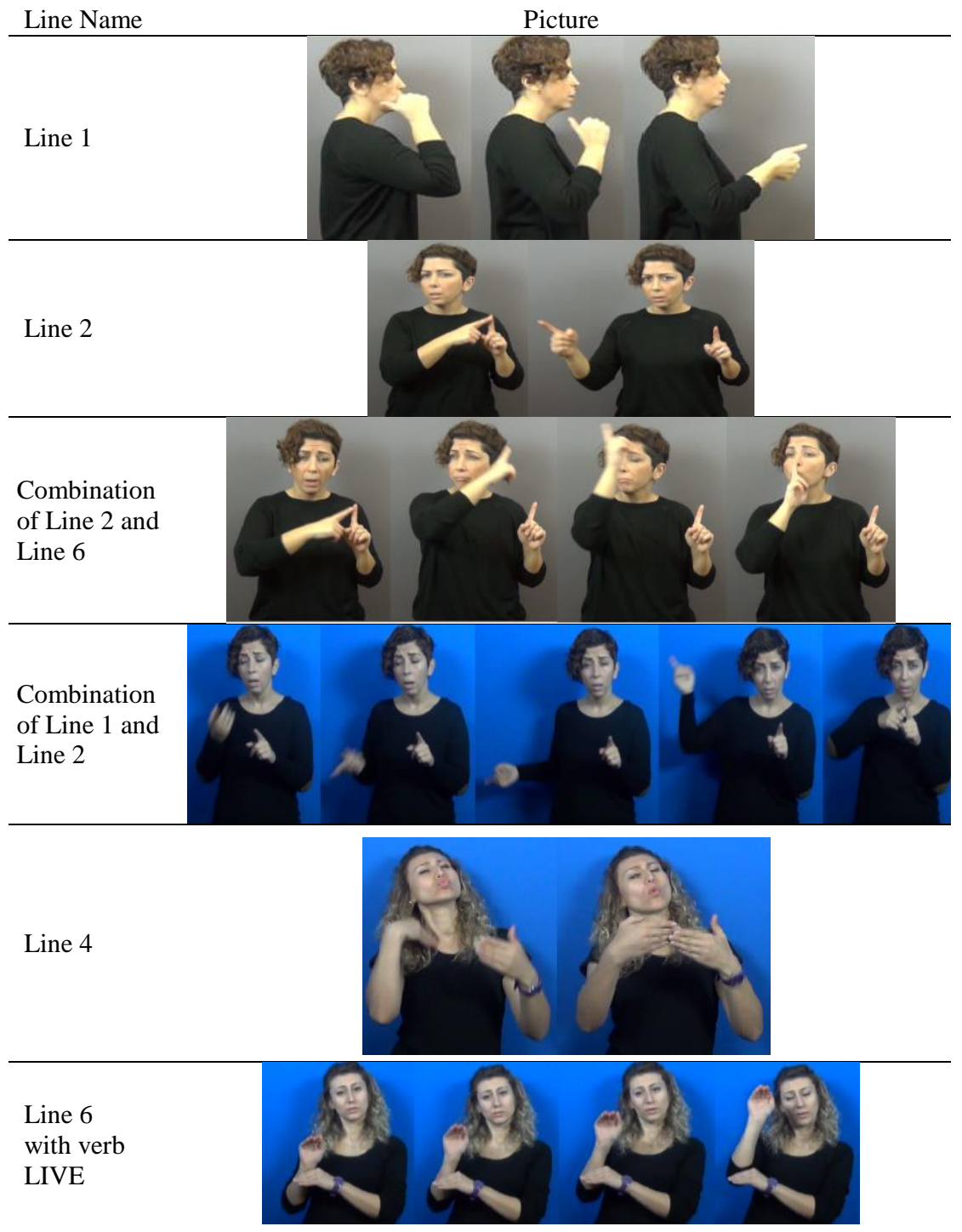


Appendix 2: The list of verbs used in the stimulus

\begin{tabular}{llll} 
Gloss & Translation & Category & Telicity \\
\hline AL & take & backward agreement & telic \\
\hline ANLAT & tell & forward agreement & atelic \\
\hline ARA & call & forward agreement & telic \\
\hline ARA & look for & plain & atelic \\
\hline AT & throw & spatial & telic \\
\hline BAŞVUR & apply & forward agreement & telic \\
\hline BEĞEN & like & plain & atelic \\
\hline BULUŞ & meet & plain & telic \\
\hline DALGA_GEÇ & make fun of & forward agreement & atelic \\
\hline DAVET_ET ${ }^{4}$ & invite & backward agreement & telic \\
\hline DENE & try & plain & atelic \\
\hline GEL & come & spatial & telic \\
\hline GIT & go & spatial & telic \\
\hline HATIRLA & remember & plain & telic \\
\hline İSTE & want & plain & atelic \\
\hline IZLE & watch & plain & atelic \\
\hline KARŞILAŞ & Run into & plain & telic \\
\hline MERAK_ET & worry & plain & atelic \\
\hline SÖYLE & tell & forward agreement & telic \\
\hline TAŞIN & move & spatial & telic \\
\hline UNUT & forget & plain & telic \\
\hline VER & give & forward agreement & telic \\
\hline YAP & make & plain & atelic \\
\hline YÜRÜ & walk & spatial &
\end{tabular}

14 For glossing conventions, underscore is used to indicate that a single sign has multi word expression in Turkish. 